\title{
MUDANÇAS NA COMUNICAÇÃO AO LONGO DA TERAPIA DE ABORDAGEM SISTÊMICA: UM ESTUDO DE CASO
}

\author{
Amanda Isabela Nórcio Scapini \\ Universidade Federal de Santa Catarina \\ Ivânia Jann Luna \\ Universidade Federal de Santa Catarina
}

\begin{abstract}
Resumo
O artigo visa explorar a mudança na comunicação de um jovem adulto e suas repercussões no contexto individual e familiar no decorrer da terapia de abordagem sistêmica. Para tal, foi realizado um estudo de caso clínico de um processo psicoterapêutico com duração de nove meses. O estudo de caso está composto pela história da família, as queixas e demandas, bem como as estratégias terapêuticas utilizadas para trabalhar os aspectos comunicacionais do paciente e a relação com sua família. Os resultados são discutidos com base no Modelo da Pragmática da Comunicação Humana e das dimensões da comunicação entre pais e filhos. Conclui-se que os recursos da psicoterapia de abordagem sistêmica contribuíram para a consolidação de mudanças nas formas de comunicação, e que eles repercutiram tanto no pleno desenvolvimento social, psíquico e relacional da pessoa atendida, quanto na dinâmica familiar.

Palavras-chave: terapia familiar; teoria da comunicação; jovens adultos.
\end{abstract}

\section{CHANGES IN THE FORMS OF COMMUNICATION THROUGHOUT THE SYSTEMIC APPROACH THERAPY: A CASE STUDY}

\begin{abstract}
This article aims to explore changes in the communication of a young adult and their impacts on individual and family context, by using the systemic therapy approach. A clinical case study was conducted for nine months to this end. This paper is composed of the family history, the complaints and demands, and the therapeutic strategies used to develop the patient's communicative aspects and his relationship with the family. The results are discussed based on the Human Communication Pragmatics Model and the dimensions of communication between parents and children. We concluded that the resources of the systemic approach psychotherapy contributed to the consolidation of changes in communication forms, and had repercussions on both the social, psychological and relational development of the young adult, as well as on the family dynamics.
\end{abstract}

Keywords: family therapy; communication theory; young adults. 


\title{
CAMBIOS EN LA COMUNICACIÓN A LO LARGO DE LA TERAPIA DE ABORDAJE SISTÉMICO: UN ESTUDIO DE CASO
}

\begin{abstract}
Resumen
El artículo objetiva presentar os cambios en las formas de comunicación de un joven adulto y sus repercusiones en el contexto individual y familiar en el curso de la terapia de abordaje sistémico. Para ello, se realizó un estudio de caso clínico referente a un proceso psicoterapéutico en un período de nueve meses. El estudio de caso está compuesto por la historia de la familia, las quejas y demandas, así como las estrategias terapéuticas utilizadas para trabajar los aspectos comunicacionales del paciente con su familia. Los resultados se discuten sobre la base del Modelo de la Pragmática de la Comunicación Humana y de las dimensiones de la comunicación entre padres e hijos. Se concluye que los recursos de la terapia sistémica contribuyeron a la consolidación de cambios en las formas de comunicación, y que ellas repercutieron en el pleno desarrollo social, psíquico y relacional de la persona atendida, como en la dinámica familiar.
\end{abstract}

Palabras clave: terapia familiar; teoría de la comunicación; adultos jóvenes.

\section{INTRODUÇÃO}

"A primeira necessidade? Comunicar-se". Madre Teresa de Calcutá.

O termo comunicação tem sua raiz etimológica no latim communicatione, que significa o ato de distribuir, repartir ou tornar comum. Ao longo do tempo e a depender do contexto ou área de conhecimento em que é utilizado, o significado desse termo pode ser compreendido de diversas formas (Beja, 2009). No presente artigo, será abordada especificamente a comunicação humana. Para fins de compreensão do fenômeno, Watzlawick, Beavin e Jackson (1967) utilizam-se da semiótica, uma teoria geral dos sinais e da linguagem. Essa teoria analisa a comunicação em três domínios distintos, porém interdependentes: a sintaxe, a semântica e a pragmática. Na sintaxe, estuda-se a transmissão da comunicação, ou seja, os canais de transmissão, problemas de codificação, redundância e demais propriedades estatísticas da linguagem. No estudo da semântica, o foco recai sobre os significados implícitos nos símbolos que constituem as mensagens. Por fim, a pragmática debruça-se sobre os efeitos da comunicação sobre o comportamento, isto é, o que se faz com e por meio da comunicação, quais as suas funções relacionais e comportamentais.

O Modelo da Pragmática da Comunicação Humana foi descrito por Watzlawick et al. (1967) no livro "Pragmática da Comunicação Humana: um estudo dos padrões, patologias e paradoxos da interação". Na obra, o processo comunicacional é explorado a partir de cinco pressupostos, chamados de axiomas da comunicação. Os axiomas permitem delinear aspectos funcionais da comunicação e inferir sobre a qualidade das relações entre as pessoas a partir da forma como se comunicam, sendo eles: 1) a impossibilidade de não comunicar; 2) toda comunicação tem um nível de conteúdo e um nível de relação, de tal maneira que o último classifica ao primeiro e é, portanto, uma 
metacomunicação; 3) a natureza de uma relação depende da ordem com que os participantes pontuam as sequencias comunicacionais entre eles; 4) os seres humanos comunicam-se digital e analogicamente; e 5) os padrões de interação podem ser simétricos ou complementares. Cada uma dessas proposições será abordada em maior profundidade ao longo do artigo.

Por ora, importa ressaltar que, na concepção pragmática, a comunicação e o comportamento tornam-se sinônimos, pois "todo o comportamento, e não somente o discurso, é comunicação, e toda comunicação - mesmo os signos que marcam a comunicação num contexto impessoal - afeta o comportamento" (Watzlawick, Beavin \& Jackson, 1973, p. 16). Desta forma, é possível compreender por que o processo de se comunicar é condição necessária para a socialização e o desenvolvimento dos seres humanos (Alarcão, 2006; Heiman, Zinck \& Heath, 2008; Portugal \& Alberto, 2010).

Ao considerar que os primeiros vínculos emocionais e afetivos ocorrem no contexto familiar, Portugal e Isabel (2013) defendem que a comunicação, especialmente nas relações familiares, pode favorecer ou prejudicar o desenvolvimento sadio das pessoas; sendo "um elemento delineador da identidade e da realidade familiar, mas também das relações que se estabelecem nesse sistema" (p. 485). A longo prazo, dificuldades comunicacionais entre pais e filhos podem acarretar em comportamentos problemáticos e no desenvolvimento de psicopatologias, além de impactar negativamente no desenvolvimento sócioemocional na vida adulta, por exemplo (Watzlawick et al., 1967; Heiman et al., 2008).

Nesse sentido, Portugal e Alberto (2010) refletem sobre o papel da comunicação na parentalidade à luz das contribuições do Modelo da Pragmática da Comunicação Humana (Watzlawick et al., 1967). Os autores apresentam evidências de que há diferenças nas formas como adolescentes e pais percebem a comunicação entre eles nesta etapa do ciclo de vida familiar. Enquanto adolescentes percebem, frequentemente, a postura comunicacional dos pais como desafiante e carregada de autoridade, proporcionando uma interação negativa entre as partes, os pais tendem a percebê-la da forma contrária, avaliando que possuem boa comunicação com seus filhos. Essa divergência de percepções pode ser problemática, uma vez que há estudos indicando que uma comunicação aberta e livre de problemas pode contribuir para a experiência de sentimentos positivos e menor conflitualidade para o adolescente, e que o autoconceito familiar positivo depende justamente da boa fluência dessa comunicação (Alarcão, 2006; Ochoa, Lopez \& Emler, 2008).

Outro estudo, realizado por Portugal e Isabel (2013) a fim de caracterizar a relação parento-filial em termos comunicacionais, identificou empiricamente as dimensões da comunicação mais destacadas por pais e seus filhos com idades entre 7 e 16 anos. Pela análise de conteúdo a partir de entrevistas em grupos focais, sete dimensões foram verificadas, sendo elas: Metacomunicação, 
Problemas Comunicacionais, Partilha de Situações Problemáticas, Atitudes Filiais, Atitudes Parentais, Afeto e Estabelecimento de Regras e Limites.

As dimensões na comunicação entre pais e filhos e o modelo da pragmática da comunicação humana são importantes para a abordagem psicoterápica sistêmica denominada de visão estratégica (Papp, 1992), que se pauta nos princípios sistêmicos (causalidade circular, globalidade e totalidade) bem como no conceito de retroalimentação negativa desenvolvida pela cibernética de primeira ordem (Esteves de Vasconcelos, 2007). Este consiste em um mecanismo homeostático que mantêm padrões comunicacionais disfuncionais na família e na rede de relacionamentos. Sendo assim, a visão estratégica compreende o comportamento do indivíduo a partir do contexto relacional em que este tem significado, sendo este recursivamente produzido a partir das interações que visam o equilíbrio das relações entre os indivíduos que constituem um sistema de relacionamento.

A terapia estratégica propõe alterações em relação a um novo modo de comunicar-se na família e que produza repercussões em vários aspectos da vida dos indivíduos a curto e longo prazo, podendo ser um fator determinante para a saúde psíquica (Segrin \& Flora, 2005). Neste sentido, quer seja desenvolvida com a família, o casal ou apenas com os membros individualmente, busca a criação de novas conexões entre os diferentes padrões relacionais.

Os estudos sobre terapia sistêmica individual com adolescentes e adultos, com base na perspectiva do ciclo de vida familiar de Carter \& McGoldrick (1995), Bowen (1998) e Boscolo \& Bertrando (2013), apontam a importância da diferenciação do indivíduo. Nesta direção, estudos brasileiros demonstram a importância da transgeracionalidade (Camicia, Silva, \& Schmidt 2016) e do processo de individuação e diferenciação de jovens adultos (Pellegrini, Silva, Barreto, \& Crepaldi, 2015) como foco da terapia com jovens adultos. Porém, não foram encontrados estudos que alinhassem essa proposta terapêutica com a população em questão à visão estratégica da terapia de abordagem sistêmica.

Neste sentido, desenvolveu-se um estudo que visa contribuir com a discussão das sete dimensões na comunicação entre pais e filhos e do modelo da Pragmática da comunicação humana a partir da compreensão de um caso clínico que foi conduzido pelos pressupostos da terapia de abordagem sistêmica estratégica. Para tanto, este artigo visa explorar a mudança na comunicação do paciente e suas repercussões no contexto individual e familiar.

\section{MÉTODO}

Este trabalho é de natureza qualitativa e caracteriza-se como um estudo de caso clínico. De acordo com Yin (2015), estudo de caso é um método que objetiva compreender fenômenos sociais complexos, preservando elementos importantes e significativos de eventos da vida real. Possui caráter indutivo e 
idiográfico, além de permitir a análise longitudinal de uma situação ou interação. Dessa forma, constitui-se uma opção adequada para a compreensão de aspectos clínicos, sobretudo os que envolvem a subjetividade, trabalhados no setting terapêutico (Serralta, Nunes \& Eizirik, 2011).

Para este estudo, serão descritas algumas demandas verificadas no caso de Henrique. A fim de preservar a confidencialidade do paciente e de sua família, os nomes utilizados no artigo serão fictícios e as informações que não são significativas para a compreensão do caso serão omitidas.

Os atendimentos clínicos desse caso foram acompanhados por uma estagiária de Psicologia, no serviço-escola de uma universidade pública do sul do Brasil. Henrique, sexo masculino, universitário, com 23 anos de idade, buscou atendimento psicoterápico em abril 2016, sendo que este perdurou até novembro deste mesmo ano. Os encontros ocorreram semanalmente, de maneira individual, com a duração média de uma hora cada. A estagiária contou com supervisões clínicas orientadas por uma professora doutora com especialidade em Terapia Familiar Sistêmica, com frequência semanal e duração aproximada de duas horas.

Para o desenvolvimento do artigo, foram utilizados os relatos dos atendimentos e supervisões, cujos conteúdos foram submetidos a uma análise narrativa (Moutinho \& Conti, 2017). Nesse estilo de análise, a narrativa é tomada como foco de estudo, de modo que os acontecimentos são organizados temporalmente e discutidos com base na literatura científica, com vistas a atender a um objetivo de pesquisa. Assim, inicialmente, será descrito o caso Henrique, de maneira sucinta, apresentando dados gerais da pessoa atendida, queixas iniciais e os motivos que a trouxeram à psicoterapia. Também será estabelecido um diálogo com os aspectos teóricos expostos na introdução, visando a compreensão das queixas e a construção da demanda clínica, bem como dos recursos terapêuticos envolvidos no processo de atendimento. No que se refere a questões éticas, no ato de inscrição para os atendimentos no serviçoescola, a pessoa atendida assinou um Termo Consentimento Livre e Esclarecido, o qual previa a utilização dos dados relativos aos atendimentos em produções científicas, resguardando-se a confidencialidade e a privacidade.

\section{RELATO DO CASO CLÍNICO}

\section{História da Família}

Henrique é o filho mais velho de Rosa e Jair, possui uma irmã, Ana. Relatou que residiu em um estado de outra região do país até seus 12 anos, quando os pais se divorciaram e a mãe, Rosa, decidiu mudar-se com os filhos para um estado da região sul do Brasil. O pai, apesar de permanecer na outra região, continuou a contribuir financeiramente com a família, de modo que Rosa 
parou de trabalhar após a mudança de cidade. O início dos conflitos com a mãe se deram logo após o divórcio, antes da mudança para um estado do sul do Brasil. Assim, Rosa parou de trabalhar e passou a dar festas em casa, beber e sair com frequência. Henrique tinha 10 anos à época. Sua postura com relação a Henrique após a mudança de cidade passou a ser de superproteção, telefonando constantemente para o filho para saber onde e com quem ele estava e se ia demorar para voltar para casa. Em pouco tempo, a avó e os tios maternos de Henrique também se mudaram para um estado do sul do Brasil, onde residem até então. Henrique manteve contato com Jair, telefonando-o semanalmente e visitando-o no período das férias escolares. No entanto, o vínculo entre pai e filho foi enfraquecendo com o passar do tempo, de modo que o conteúdo dos diálogos entre eles passou a ser superficial. Henrique relatou que conversava com o pai apenas sobre questões financeiras e assuntos banais do dia-a-dia, evitando que Jair tomasse conhecimento de assuntos íntimos, tanto os seus particulares, quanto os que envolvem a mãe, a irmã e a avó materna. A família nuclear de Henrique passou a se configurar como monoparental, dado que a mãe passou a assumir a maior parte dos papéis parentais, à exceção da sustentação financeira.

\section{Motivos apresentados para a busca por atendimento}

Henrique procurou 0 atendimento psicoterápico sem o conhecimento prévio dos familiares, alegando dificuldade no contexto das relações ocasionais, sociais e íntimas, como colegas de aula, parceiros amorosos, professores, mãe, pai, irmã, avó, etc. Também relatou um relacionamento familiar conflituoso, principalmente com a mãe e a avó materna. No contexto destas relações íntimas, mas não só, Henrique alegou sofrimento psíquico, principalmente ansiedade, sentimentos de vazio e despersonalização (não se reconhecendo nos contatos interpessoais que realizava), bem como rigidez comportamental e retraimento social (quando se relacionava com uma pessoa).

\section{Análise da demanda clínica}

Os encontros terapêuticos iniciais foram dedicados à exploração das queixas bem como à construção de qual seria a demanda clínica. Observou-se que Henrique mostrava-se expressivo na forma de falar, num estilo quase teatral para comunicar a sua intenção de estar na psicoterapia, apesar de definir-se como tímido. O uso do termo "expressivo", nessa situação, refere-se à utilização exacerbada de gestos corporais, de expressões faciais e de tonalidades de voz. Nas sessões posteriores, utilizadas para explorar as queixas iniciais, observou-se que a utilização de metáforas em sua fala fazia-se constante (o paciente verbalizava, por exemplo, "minha amiga pintou meu sorriso de preto com suas palavras" para comunicar à terapeuta que o conteúdo da comunicação da amiga havia alterado negativamente seu humor). Observou-se que a nomeação de 
sentimentos se dava de forma idiossincrática, pois Henrique preferia se referir ao que estava sentindo usando outros idiomas ou cores, por exemplo: "hoje estou lilás", para dizer que nada estava preocupando-o naquele dia; "Je suis désolé", traduzido do francês como "eu sinto muito", para lamentar algo ruim que havia ocorrido.

Para compreender o modo preferencial de Henrique em comunicar-se, precisou-se refletir sobre o nível da simbolização presente na sua comunicação, ou seja, o quarto axioma de Watzlawick et al. (1967), pois ainda que usasse códigos indecifráveis, ele estava tentando comunicar sentimentos, pensamentos, crenças e sofrimento. A comunicação tem uma vertente digital e uma vertente analógica. A primeira é mais objetiva e precisa, geralmente verbal e utilizada para comunicar conteúdos desprovidos de emoções e sentimentos (mas não necessariamente). Já a segunda dá margem a uma interpretação mais subjetiva daquilo que está sendo transmitido digitalmente, em função da simbolização (Watzlawick et al., 1967).

Nas sessões iniciais observou-se também que Henrique vivia constantemente situações típicas do início da adolescência, especialmente se tratando de relacionamentos amorosos, bem como a necessidade de se diferenciar da família através do delineamento de uma personalidade própria, idealizada e "teatralizada" por ele, bem como o anseio de (re)descobrir sua sexualidade. Porém, em meio à turbulência de pensamentos - também típica de um adolescente -, Henrique dizia sentir-se confuso e inseguro, incapaz de perceber-se compreendido nos seus sentimentos pela sua mãe. Deste modo, outro foco de exploração e compreensão da demanda para atendimento foi a relação dele com a sua mãe.

Henrique relatava ter dificuldades para iniciar e aprofundar qualquer diálogo com a mãe, pois ele acreditava que qualquer conteúdo comunicado seria um desencadeador de ansiedade e retroalimentaria a preocupação de Rosa, resultando em mais proteção. Ele também relatou a pouca tolerância às falas da mãe, agindo com agressividade quando ela se reportava a ele, e com isso recebia respostas da mesma maneira. Esse quadro, rotineiro para o paciente, pode ser categorizado na dimensão "problemas comunicacionais" da comunicação paterno-filial descrita por Portugal e Isabel (2013). Segundo os autores, problemas comunicacionais surgem quando os membros da família focam em aspectos negativos de comunicação e interação. A dimensão "atitudinal", que diz respeito à gestão da comunicação feita tanto pelos pais quanto pelos filhos, também se aplica no contexto relatado. Ao passo que Rosa faz movimentos de preocupação e proteção, Henrique tem atitudes de autodefesa e introversão. A gestão da comunicação, nesse caso, era feita individualmente por cada elemento e tinha repercussões negativas na relação. Tal situação remete, também, ao segundo axioma de Watzlawick et al. (1967), que refere que toda comunicação envolve dois níveis, o de conteúdo e o da 
relação. O fato de Henrique e a mãe terem entrado em discussões agressivas sobre, por exemplo, o horário que ele chegaria em casa ou de quem estava acompanhado, reflete que debatiam em nível de conteúdo aspectos que, na verdade, eram relacionais. No caso, a dificuldade da mãe em compreender as mudanças no ciclo de vida familiar, ao perceber que o filho vinha adquirindo autonomia e não dependia mais tanto de seus cuidados como quando era criança.

Sendo assim, ansiando por outras formas de comunicar as suas necessidades de acordo com o seu ciclo vital e familiar, Henrique passou a utilizar filmes para emitir mensagens à Rosa a respeito de sua autonomia. $\mathrm{Na}$ percepção dele, ambos compreendiam o sentido que cada filme tinha no contexto em que era exibido, mas nenhum dos dois explicitava nada a respeito, sendo o filme a maneira de mãe e filho se comunicarem. Henrique relatou ainda que, nos momentos em que não estavam assistindo filmes, ele e a mãe assumiam-se como personagens e se comunicavam através de porquinhos de brinquedo. Ambos interpretavam personagens fixos, com nomes próprios, adaptando as vozes como em uma brincadeira infantil. Assim, o diálogo ocorria entre os personagens representados pelos porquinhos, não entre mãe e filho. Nenhum aspecto da relação parento-filial era debatido pelos personagens. As conversas giravam em torno de assuntos de rotina (por exemplo: "Como choveu essa semana! Espero que a chuva traga frio, porque eu passo mal no calor"), o que Henrique nomeou de "assuntos de elevador". É possível relacionar esse recurso comunicacional com a dificuldade da mãe em compreender as mudanças no ciclo de vida familiar, mencionada previamente neste artigo. Mais uma vez, ao considerar tanto o recurso dos filmes quanto o dos personagens de porquinhos, e retomando o quarto axioma de Watzlawick et al. (1967) sobre as vertentes analógica e digital, verifica-se que a comunicação entre Henrique e a mãe assumia uma configuração predominantemente analógica; sujeita, portanto, a distorções.

Analisou-se que as queixas iniciais trazidas por Henrique à terapia poderiam estar relacionadas ao impacto negativo que o uso extensivo do modo analógico do paciente em comunicar as suas necessidades, emoções e desejos. Sendo assim, sustentaram-se três objetivos terapêuticos para conduzir a terapia estratégica individual como: tornar congruente a comunicação familiar; estimular a comunicação com as demais pessoas no que se refere ao uso das vertentes digital e analógica da comunicação e estimular o processo de diferenciação do paciente. Deste modo, serão apresentadas e discutidas na sequência as principais estratégias e recursos que nortearam o atendimento clínico a fim de alcançar esses objetivos. 


\section{DESENVOLVIMENTO DO ATENDIMENTO}

No contexto clínico traçaram-se estratégias terapêuticas, que sustentadas pela psicoterapia de abordagem estratégica individual com jovens adultos, possibilitaram trabalhar os aspectos comunicacionais que vinham limitando as interações familiares e sociais de Henrique. Nos primeiros seis meses de acompanhamento, optou-se por focar a terapia exclusivamente no paciente, visando um nível de estabilidade emocional e clareza de sentimentos e pensamentos satisfatórios, para promover, posteriormente, uma sessão com a participação de familiares visando intervenções na comunicação e diferenciação familiar.

Deste modo foram utilizados recursos terapêuticos que visavam auxiliar Henrique a nomear seus sentimentos. Como mencionado previamente neste artigo, era comum que o paciente usasse expressões corporais, faciais e estéticas, diferentes tonalidades de voz e figuras de linguagem para comunicarse, recorrendo a cores, idiomas ou outros recursos para tal. A técnica "Emoções no dia a dia" (Rosset, 2006), que consiste em solicitar que o paciente redija todos os dias um breve relato sobre como se sente, num exercício de nomear sentimentos e emoções, foi utilizada para trabalhar tal aspecto. Com a execução da tarefa, Henrique demonstrou melhoras graduais na forma como percebia e interpretava seus sentimentos. Relatou dificuldades nos primeiros dias, apoiando-se em recursos como letras de músicas e poemas já existentes para expressar-se. O objetivo da atividade proposta era que a comunicação do paciente possuísse também a vertente digital.

Na vertente analógica, quando, por um viés de interpretação, a tradução subjetiva não é equivalente ao conteúdo que pretende ser passado, ocorre a distorção comunicacional (Portugal \& Alberto, 2010). Num contexto psicoterápico é fundamental que o conteúdo emitido pelo paciente seja compreendido com fidedignidade pelo terapeuta, reduzindo essas distorções que, em contextos rotineiros, podem culminar em conflitos. Portanto, buscou-se ao máximo durante a terapia estimular para que Henrique objetivasse e traduzisse o que pretendia comunicar, através de perguntas como "O que significa para você estar lilás?", "Que sentimentos a cor lilás expressa?" ou, ainda, "Que emoções sente uma pessoa que está lilás?". A dificuldade apresentada pelo paciente ao tentar responder tais questionamentos, especialmente nos primeiros meses do processo terapêutico, possibilitou a compreensão da repercussão dos estilos comunicacionais em outras dimensões de sua vida.

Ao considerar que as formas analógicas já usadas pelo paciente também são formas de comunicação, e dada a impossibilidade de não comunicar postulada no primeiro axioma (Watzlawick et al., 1967), tomou-se o cuidado de não desestimular seu uso. Ao passo que Henrique alcançasse um equilíbrio de ambas as vertentes comunicacionais analógica e digital, seria possível trabalhar 
a metacomunicação. Isso porque as distorções comunicacionais seriam reduzidas e os diálogos com o paciente ocorreriam de modo mais fluido e objetivo.

$\mathrm{Na}$ Teoria da Comunicação, o termo metacomunicação é conceituado como "comunicação sobre a comunicação" (Gomes, Bolze, Bueno \& Crepaldi, 2014, p. 12). Portugal e Isabel (2013) categorizam a metacomunicação como uma das dimensões da comunicação parento-filial, que se desdobra em diversas subcategorias. De acordo com os autores, numa perspectiva teórica, tal dimensão "está relacionada com a troca de mensagens positivas entre os elementos da família possibilitando uma melhor gestão dos fatores de estresse" (p. 485). Assim, a clareza comunicacional, a clarificação de papéis e a liberdade de expressão são características alcançáveis por meio da metacomunicação que podem contribuir para uma performance comunicacional de qualidade entre os elementos da família.

Ao avaliar que o paciente se encontrava em um nível de estabilidade emocional e clareza de sentimentos e pensamentos satisfatórios, verificou-se com ele a possibilidade de convidar sua mãe para participar da terapia. Ao convidar a mãe, o paciente julgou pertinente que a irmã participasse também. Não apenas por ser um estímulo a mais para que Rosa aceitasse comparecer, mas também por considerar que Ana estava igualmente inserida naquele sistema e suas contribuições poderiam ser valiosas.

O principal objetivo do encontro era, novamente, a metacomunicação. Buscou-se com essa estratégia criar um espaço "seguro", na presença da terapeuta, para que o diálogo fosse estimulado. Logo, tratava-se de uma oportunidade para trabalhar alguns axiomas e dimensões da comunicação. Das contribuições de Watzlawick et al. (1967), pretendeu-se deslocar as discussões do nível do conteúdo para o nível relacional (segundo axioma). Portugal e Alberto (2010) e Alarcão (2006) defendem que quando uma comunicação se enrijece e dá origem a distorções e mal-entendidos, a metacomunicação pode ser estratégia central por determinar e clarificar como devem ser interpretados os comportamentos relacionais. Complementando, o terceiro axioma, que refere que a pontuação da comunicação organiza os eventos comunicacionais, contribui com o caso no sentido de alinhar as percepções dos elementos da família (por exemplo, sobre o ciclo de discussões citado anteriormente, Henrique percebia a superproteção da mãe como elemento primeiro que desencadeava malentendidos, enquanto Rosa atribuía o início dos conflitos às respostas agressivas do filho; caindo num círculo culposo e disfuncional). Com a oportunidade de diálogo que outrora era rara e turbulenta, a família poderia organizar os eventos comportamentais para evitar distorções, focando no aspecto relacional (o ciclo de vida familiar, neste exemplo).

O quinto axioma postula que a comunicação envolve dois tipos de interação: simétrica (em que os elementos da família colocam-se no mesmo nível e habilitam-se a refletir os comportamentos uns dos outros) (Alarcão, 
2006) e complementar (em que um elemento complementa a comunicação do outro, promovendo e reforçando as diferenças comunicacionais) (Watzlawick et al., 1967). Com a participação de Rosa e Ana na sessão de psicoterapia, esperava-se delimitar as situações mais adequadas para cada modelo de interação. Assim, a família poderia usufruir de flexibilidade e adaptar os estilos mais pertinentes a cada situação, atentando para não tender para o extremismo ou rigidez de nenhum lado. De modo geral, seriam reduzidas as causas lineares da interação, ao passo que haveria reconhecimento da recursividade e circularidade.

Exploraram-se, na ocasião da vinda da mãe e da irmã para o encontro terapêutico, três dimensões da comunicação parento-filial de Portugal e Isabel (2013): a partilha de soluções problemáticas, estabelecimento de regras e limites e o afeto. Partilhar soluções problemáticas, como questões íntimas e pessoais relacionadas a amizades, trabalho, família etc., faz parte de uma comunicação saudável. No entanto, demanda um balanceamento entre a privacidade e a confiança parento-filial dos elementos. No caso de Henrique, ele não sentia confiança na mãe o suficiente para relatar suas situações a ela. Segundo seus relatos em terapia, também sentia como se sua mãe não confiasse em sua autonomia, pois invadia sua privacidade com ligações e mensagens inoportunas. Por outro lado, a mãe relatou que assumia esses comportamentos justamente pelo fato de Henrique nunca partilhar nada sobre sua vida particular com ela, o que a deixava insegura e com falta de confiança. Nota-se, aqui, que a metacomunicação e a utilização do terceiro axioma, que pontua os eventos comunicacionais (Watzlawick et al., 1967), são complementares à dimensão "partilha de situações problemáticas".

A dimensão seguinte, do estabelecimento de regras e limites, vem ao encontro desse processo. Portugal e Isabel (2013) delineiam que esse é um elemento integrado na relação cotidiana de pais e filhos e consiste na possibilidade de negociação entre os elementos da família. De acordo com os autores, a advertência é frequentemente usada como estratégia pelos pais para delimitar comportamentos dos filhos. O esclarecimento dessa possibilidade à família de Henrique, conforme seu relato posterior à sessão em que a mãe e a irmã participaram, "abriu novos horizontes" quanto às formas de diálogo e proporcionou os sentimentos de respeito e privacidade na família.

Por fim, a dimensão do afeto pressupõe demonstrações verbais e nãoverbais de afeto (que geralmente ocorrem simultaneamente) (Portugal \& Isabel, 2013). Tais demonstrações configuram-se como comportamentos adaptativos, que têm repercussões nas competências sociais e comunicacionais tanto dos pais quanto dos filhos (Segrin \& Flora, 2005). Ao longo do processo psicoterápico, por várias vezes Henrique mencionou a ausência de demonstrações afetuosas em sua família. O contrário, porém, fazia-se constante: sua avó, que também se mudou da outra região do país para um estado do sul, tinha o hábito de fazer 
críticas e comentários depreciativos a respeito de Rosa e dos filhos. Questionar sobre as manifestações de afeto entre os elementos da família durante a sessão e encerrar reforçando a importância desses gestos, desde que sinceros, foi a última alternativa utilizada para que a família conseguisse progredir em seu aspecto comunicacional.

No decorrer do período da psicoterapia, o paciente apresentou melhoras graduais e significativas com relação ao uso extensivo da comunicação analógica, posto que esta trazia efeitos e identificados por ele como negativos, também no contexto familiar. Em seus relatos, afirmou que adquiriu a capacidade de compreender seus sentimentos. Dessa forma, conseguiu controlá-los e agir com mais consciência. A mudança trouxe várias implicações no seu comportamento. Henrique passou a participar de festas e encontros de amigos; desenvolveu habilidades comunicacionais, através das quais conseguiu maior socialização com os colegas de graduação; comprou um aparelho celular (que antes se recusava a fazer, pois entendia que, possuindo um aparelho, teria que interagir com pessoas e não se sentia seguro para isso); envolveu-se em relacionamentos amorosos, superando o temor em não conseguir demonstrar sua afetividade, sendo que um dos relacionamentos chegou a durar quase dois meses; e conseguiu uma bolsa como monitor de disciplina, na qual se mostrou envolvido e relatou estar seguro para lecionar e tirar dúvidas de colegas (algo que demanda elevada capacidade de comunicação). Essas novas experiências caracterizam o processo de diferenciação; mais especificamente, o estágio de lançamento do jovem adulto (Camicia et al., 2016), que envolve a resolução de tarefas desenvolvimentais distintas daquelas que costumavam ser realizadas por Henrique anteriormente, em sua família de origem. A diferenciação saudável envolve uma separação sem rompimento, acoplando um senso de responsabilidade emocional e financeira pelo "eu", que pode ser observada nesse caso.

Após sete meses de psicoterapia, fazendo comparativo com as atividades de escrita para nomear os sentimentos e emoções, propostas em junho, Henrique disse que não se enxergava mais como sendo a pessoa que escreveu aquilo: já possuía atitudes e posturas diferentes positivamente. Sentiu necessário realizar a atividade novamente para atualizar o material. Foi notável, também, a redução das figuras de linguagem e do excesso de expressões corporais e faciais em seus relatos.

Com relação à família, o paciente passou a manter um relacionamento mais estável e funcional. A própria presença da mãe na sessão de psicoterapia foi considerada por Henrique como uma conquista decorrente do seu progresso comunicacional e relacional. A partir da sessão em que a mãe e a irmã participaram, ele relatou que houve mais diálogo em casa. O paciente conseguiu compartilhar situações de seu dia-a-dia e ambos estabeleceram limites e regras a fim de respeitar a privacidade e evitar conflitos. Com relação a isso, em recente estudo a respeito da diferenciação adulto-jovem, Pellegrini et al. (2015) 
destacam a necessidade do estabelecimento de fronteiras claras entre pais e filhos para que a transição adulto-jovem ocorra de forma saudável, de modo a reduzir o estresse familiar. As autoras ressaltam, também, que a busca dos filhos por outras ocupações que preencham espaços antes tomados pela criação em casa pode ser positiva durante períodos de mudança típicos da adultez jovem. Nesse sentido, é importante que existam espaços (também físicos) para que novos significados sejam atribuídos a acontecimentos históricos na família, perdendo-se a rigidez da relação e facilitando-se a comunicação (Pellegrini et al., 2015).

Esses aspectos evidenciados na literatura puderam ser verificados na relação familiar em questão após o atendimento conjunto: Mãe e filho continuaram vendo filmes, mas não mais com o objetivo de emitir e receber mensagens por meio deles. A atividade passou a ter função de lazer. Os porquinhos de brinquedo foram, aos poucos, perdendo sua função, até que deixaram de ser utilizados como personagens. Henrique passou ainda a incentivar a mãe para que arrume trabalhos, ainda que pequenos (como vender peças que ela confecciona em crochê ou realizar a correção de trabalhos acadêmicos, já que tinha grande domínio da língua portuguesa), e ela de fato o fez. Rosa começou a demonstrar mais confiança no filho. Não telefonava mais com tanta frequência quando Henrique saía de casa e aceitava que ele saísse com os novos amigos do curso sem tantos questionamentos. Isso fortaleceu o vínculo entre eles, delimitou/esclareceu algumas fronteiras e contribuiu para o processo de diferenciação de Henrique. Como resultado, o diálogo foi facilitado, possibilitando a integração da irmã à relação de mãe e filho - antes Ana percebia a relação conflituosa de Rosa e Henrique e se distanciava ou, quando necessário, posicionava-se em defesa da mãe.

\section{CONSIDERAÇÕES FINAIS}

A descrição e compreensão do caso, exposto neste artigo, viabiliza algumas conclusões sobre as mudanças na forma de comunicação e suas repercussões no contexto individual e familiar a partir do alcance dos três objetivos terapêuticos delineados para a psicoterapia de Henrique. Foram esses: a congruência da comunicação familiar; o uso das vertentes digital e analógica da comunicação e o processo de diferenciação em relação à família de origem.

Ao analisar de modo amplo a comunicação de Henrique, foi possível perceber que o paciente passou a utilizar os axiomas da comunicação a seu favor. Diminuiu significativamente a linguagem analógica e incorporou a digital, o que reduziu as distorções comunicacionais nas mensagens emitidas por ele, facilitando sua socialização. Nas relações familiares, com o aumento da confiança entre os elementos da família e o estabelecimento de um canal de diálogo, a comunicação equilibrou-se entre conteúdo e relação; e os eventos 
comunicacionais foram, assim, organizados pontualmente. Alcançadas tais mudanças, também foi possível distinguir em que momentos a relação paternofilial deveria ser simétrica ou complementar. Dessa forma, dimensões como o estabelecimento de limites, a partilha de situações problemáticas, as demonstrações de afeto e metacomunicação foram incorporadas na dinâmica comunicacional da família, enquanto a dimensão "problemas comunicacionais" foi reduzida a um nível saudável. Porém, não foi possível perceber, de modo explícito, quais foram as mudanças nas atitudes filiais e parentais durante 0 processo psicoterapêutico. O que se percebeu foi a mudança na postura comunicacional do paciente com relação aos seus familiares, o que imprimiu uma nova dinâmica ao exercício da parentalidade efetivada pela mãe.

Senso assim, se considera de extrema relevância que a comunicação assuma o tema central na avaliação da relação paterno-filial, não apenas com o objetivo de diagnosticar, mas de promover mudanças visando uma configuração familiar mais positiva e adequada. Corroborando Boechat, Cabral e Souza (2015) e Segrin e Flora (2005), relações interpessoais na família devem ser baseadas em uma comunicação que aceite, qualifique e confirme as pessoas num convívio familiar. A metacomunicação é fundamental para tal: quando pessoas podem comunicar o que sentem e pensam (e o que pensam sobre o que sentem e pensam), tornam-se capazes de organizar e discriminar suas falas, evitando distorções e conflitos. Com maior assertividade na comunicação, canais que permitam espontaneidade, limites, franqueza, e que respeitem a privacidade e a circularidade das relações, a interação atinge um nível ótimo.

Além disso, visualizou-se no caso discutido que a participação de familiares na terapia individual foi de grande contribuição e valia para todos os indivíduos. Deste modo, sugere-se que novos estudos sejam realizados sobre terapias individuais de jovens adultos com a participação de membros da família ou da rede de relacionamentos, a fim de compreender as repercussões desta no contexto de relacionamentos mais amplos, evidenciado o caráter transformador da terapia individual para as dinâmicas relacionais.

\section{DECLARAÇÃO DE CONFLITO DE INTERESSES}

Não há conflito de interesses.

\section{REFERÊNCIAS}

Alarcão, M. (2006). (Des)equilíbrios Familiares (3a ed.). Coimbra: Quarteto.

Beja, M. J. G. P (2009). Escola e família: Da inevitabilidade da comunicação à construção de uma realidade relacional. (Tese de doutorado). Universidade da Madeira, Portugal. 
Boechat, I. T., Cabral, H. L. T. B., \& Souza, C. H. M. (2015). A comunicação na família caracterizada pela pseudomutualidade e pelo duplo vínculo. Revista Transformar, (7), 227-238.

Boscolo, L., \& Bertrando, P. (2013). Terapia sistêmica individual: Manual prático na clínica. Belo Horizonte, MG: Artesã.

Bowen, M. (1998). A reação da família à morte. In. F. Walsh, \& M. McGoldrick (1998). Morte na família: Sobrevivendo às perdas (pp. 105-117). Porto Alegre, RS: Artmed.

Camicia, E. G., Silva, S. B. D., \& Schmidt, B. (2016). Abordagem da transgeracionalidade na terapia sistêmica individual: Um estudo de caso clínico. Pensando famílias, 20(1), 68-82.

Carter, B., \& McGoldrick, M. (1995). As mudanças no ciclo de vida familiar: Uma estrutura para a terapia familiar. Porto Alegre, RS: Artes Médicas.

Esteves de Vasconcelos, M. J. (2007). A "teoria da comunicação humana" na abordagem sistêmica da família. In J. G. Aun, Vasconcellos E. M. J., \& S. V. Coelho, Atendimento Sistêmico de Famílias e Redes Sociais. O Processo de Atendimento Sistêmico (pp. 487-519). $2^{a}$ ed. Belo Horizonte, MG: Ophicina da Arte \& Prosa.

Gomes, L. B., Bolze, S. D. A., Bueno, R. K., \& Crepaldi, M. A. (2014). As origens do pensamento sistêmico: Das partes para o todo. Pensando Famílias, 18(2), 3-16.

Heiman, T., Zinck, L. C., \& Heath, N. L. (2008). Parents and youth with learning disabilities. Perceptions of relationships and communication. Journal of Learning Disabilities, 41(6), 524-534. doi:10.1177/0022219408317860

Moutinho, K., \& De Conti, L. (2017). Análise narrativa, construção de sentidos e identidade. Psicologia: Teoria e Pesquisa, 32(2), 1-8. doi:10.1590/0102$3772 \mathrm{e} 322213$

Ochoa, G. M., Lopez, E. E., \& Emler, N. P. (2008). Adjustment problems in the family and school contexts, attitude towards authority, and violent behaviour at school in adolescence. Family Therapy, 35(2), 93-108.

Papp, P. (1992). O dilema da mudança. Porto Alegre, RS: Artes Médicas.

Pellegrini, P. G., Silva, I. M., Barreto, M., \& Crepaldi, M. A. (2015). Diferenciação do adulto jovem: Um estudo de caso em atendimento familiar. Pensando Famílias, 19(1), 114-129.

Portugal, A., \& Alberto, I. (2010). O Papel da Comunicação no Exercício da Parentalidade: Desafios e especificidades. Psychologica, (2), 387-400.

Portugal, A., Isabel, A. M. (2013). A comunicação parento-filial: Estudo das dimensões comunicacionais realçadas por progenitores e por filhos. Psicologia: Reflexão e Crítica, 26(3), 479-48. doi:10.1590/S010279722013000300007.

Rosset, S. M. (2006). 123 Técnicas de Psicoterapia Relacional Sistêmica. Belo Horizonte, MG: Editora Artesã.

Segrin, C., \& Flora, J. (2005). Family communication. London: Lawrence Erlbaum. 
Serralta, F. B., Nunes, M. L. T., \& Eizirik, C. L. (2011). Considerações metodológicas sobre o estudo de caso na pesquisa em psicoterapia. Estudos de Psicologia, 28(4), 501-510. doi:10.1590/S0103-166X2011000400010.

Watzlawick, P., Beavin, J. H., \& Jackson, D. D. (1967). Pragmática da comunicação humana: Um estudo dos padrões, patologias e paradoxos da interação. São Paulo, SP: Editora Cultrix.

Watzlawick, P., Beavin, J. H., \& Jackson, D. (1973). Pragmática da comunicação humana: Um estudo dos padrões, patologias e paradoxos da interação (9a ed.). São Paulo, SP: Cultrix.

Yin, R. K. (2015). Estudo de Caso: Planejamento e Métodos. São Paulo, SP: Bookman editora.

Sobre as autoras

Amanda Isabela Nórcio Scapini é psicóloga e mestranda em Psicologia pela Universidade Federal de Santa Catarina. E-mail: amandascapini@gmail.com Ivânia Jann Luna é professora do Departamento de Psicologia da Universidade Federal de Santa Catarina e do Mestrado Profissional em Saúde Mental e Atenção Psicossocial da UFSC. Com formação em Psicologia, Terapia Familiar, Mestrado em Psicologia Clínica pela Pontifícia Universidade Católica de São Paulo e Doutorado em Psicologia pela Universidade Federal de Santa Catarina. E-mail: ivaniaj.।@ufsc.br

A contribuição de cada autor pode ser atribuída como se segue: A.I.N.S e I.J.L contribuíram para a conceitualização, investigação e visualização do artigo; A.I.N.S. fez a redação inicial do artigo (rascunho) e I.J.L. é a responsável pela redação final (revisão e edição). Não houve financiamento.

Recebido em: 13/09/2017

$1^{\text {a }}$ revisão em: $18 / 12 / 2017$

Aceito em: $15 / 04 / 2018$ 